\title{
LETTERS
}

\section{Consider patient risk factors for melanoma when prescribing antihypertensives}

Drucker and colleagues provide a great paper $^{1}$ that raises questions about antihypertensive medications and adverse effects. The adjusted hazard ratio for melanoma with thiazide exposure is quite high at 1.34 (95\% confidence interval 1.01-1.78). ${ }^{1}$

In comparison, the baseline incidence rate for melanoma among men 40-44 years old is 23.50 per $100000 .^{2}$ Therefore, a very rough translation of hazard ratios (with apologies to all biomedical statisticians) shows that prescribing thiazides increases the risk of melanoma by about $34 \%$, increasing the incidence rate from 23.5 to 31.49 per 100000 people.

That means if 100000 people were prescribed hydrochlorothiazide, then about 8 more people (plus or minus the confidence interval) would get melanoma - a number needed to harm of about 12500 people per year. If the patient had a tenfold greater risk of melanoma, based on skin colour, family history and so on, the number needed to harm becomes 1250 people. For some patients, that may cross the decision threshold of whether or not to take thiazide.

I would appreciate someone checking my "back of the envelope" numbers, but if they are correct, this paper shows that providers should be considering melanoma risk in our review of drug options for patients with hypertension.

\section{Martin Dawes MD MBBS}

Family physician, University of British Columbia, Vancouver, BC
Cite as: CMAJ 2021 June 21;193:E996. doi: $10.1503 / \mathrm{cmaj} .78786$

\section{References}

1. Drucker AM, Hollestein L, Na Y, et al. Association between antihypertensive medications and risk of skin cancer in people older than 65 years: a population-based study. CMAJ 2021;193:E508-16.

2. Fears TR, Guerry D, Pfeiffer RM, et al. Identifying individuals at high risk of melanoma: a practical predictor of absolute risk. J Clin Oncol 2006;24: 3590-6.

\section{Competing interests: None declared.}

Content licence: This is an Open Access article distributed in accordance with the terms of the Creative Commons Attribution (CC BY-NC-ND 4.0) licence, which permits use, distribution and reproduction in any medium, provided that the original publication is properly cited, the use is noncommercial (i.e., research or educational use), and no modifications or adaptations are made. See: https://creativecommons.org/ licenses/by-nc-nd/4.0/ 